\title{
VOLUME DE RECIPIENTES E COMPOSIÇÃO DE SUBSTRATOS PARA PRODUÇÃO DE MUDAS DE MAMONEIRA
}

\author{
Recipients volume and substrate composition for castor seedlings production
}

\author{
Rosiane de Lourdes Silva de Lima', Liv Soares Severino ${ }^{2}$, Maria Isabel de Lima Silva ${ }^{3}$, \\ Leandro Silva do Vale ${ }^{4}$, Napoleão Esberard de Macêdo Beltrão ${ }^{2}$
}

\begin{abstract}
RESUMO
A mamoneira (Ricinus communis L.) é uma oleaginosa bem adaptada ao cultivo na região semi-árida por sua rusticidade e resistência ao estresse hídrico. Seu plantio é tradicionalmente feito por sementes, mas o uso de mudas pode se tornar atraente como estratégia para melhor aproveitamento da curta estação chuvosa. Para adoção desta tecnologia, a definição de aspectos técnicos como volume de recipientes, composição do substrato e período de permanência da muda no viveiro são fundamentais para o êxito da técnica. Conduziu-se experimento em casa-de-vegetação da Embrapa Algodão em Campina Grande, com sementes da cultivar de mamona de porte médio BRS Nordestina, em delineamento de blocos casualizados com 4 repetições e 25 tratamentos em distribuição fatorial $5^{2}$, sendo os fatores cinco volumes de recipientes e cinco composições de substratos. Entre 15 e 43 dias após a emergência (DAE) foram feitas cinco coletas destrutivas semanais para obtenção de dados de altura, diâmetro caulinar, área foliar, número de folhas e matéria seca da parte aérea e radicular. Com os dados obtidos calculou-se o tamanho da folha. Detectaram-se efeitos significativos dos tratamentos em todas as variáveis estudadas. O crescimento das mudas estabilizou-se aproximadamente aos 36 DAE, independente do volume do recipiente. Os substratos compostos por mistura de areia com esterco bovino ou casca de amendoim propiciaram o melhor crescimento das mudas, enquanto aqueles contendo bagaço de cana ou mucilagem de sisal foram os piores. Recipientes de $2 \mathrm{~L}$ de volume foram os mais adequados para a produção de mudas de mamoneira.
\end{abstract}

Termos para indexação: Ricinus communis; bagaço de cana, casca de amendoim, esterco bovino, mucilagem de sisal, cama de frango.

\begin{abstract}
Castor (Ricinus communis L.) is an oilseed crop well adapted for growing at semi-arid region for its rusticity and resistance to water deficit. It is usually planted by seeds, but planting by seedling can become attractive as a strategy for better use of the short rainy season. Before the adoption of this technology some aspects have to be set in order to succeed, such as recipient volume, substrate composition and period of seedling at nursery. A trial was run in greenhouse at Embrapa Algodão, Campina Grande, Paraíba State, Brazil, in a randomized block design with four replications and 25 treatments in $5^{2}$ factorial distribution of five recipient volumes and five substrate compositions. Between 15 and 43 days after emergence, five destructive measurements were weekly performed for obtaining data on plant height, stem diameter, leaf area, number of leaves and dry weight of shoot and roots. Significant effects of treatments were detected on all variables analyzed. Seedlings growth stabilized about 36 days after emergence regardless recipient volume. Substrates composed by soil mixed to peanut hulls or bovine manure propitiated the best seedlings growth, while those ones containing sugarcane bagasse or agave mucilage were the worst. Recipients with $2 \mathrm{~L}$ of volume were the most appropriated to castor seedlings production.
\end{abstract}

Index terms: Ricinus communis; sugarcane bagasse, peanut hull, bovine manure, agave mucilage, poultry litter.

(Recebido para publicação em 14 de abril de 2005 e aprovado em 6 de fevereiro de 2006)

\section{INTRODUÇÃO}

Entre as oleaginosas cultivadas no Brasil, a mamoneira destaca-se pela rusticidade e adaptabilidade a condições adversas de clima e solo, pelo rápido crescimento, elevada produção e considerável teor de óleo em suas sementes. Esta espécie é possivelmente originária da Etiópia ou da Ásia e apresenta grande potencial produtivo, notadamente em áreas semi-áridas que dispõem de poucas alternativas agrícolas viáveis.
A produção de mudas de mamoneira não é uma prática adotada pelos produtores de mamona, mas pode se tornar uma alternativa para o plantio desta cultura na região semi-árida como estratégia para melhor aproveitamento da curta estação chuvosa. Mamoneiras de porte médio, recomendadas para regiões de pouca disponibilidade hídrica, são plantadas em populações de 3 a $4 \mathrm{mil} \mathrm{pl} / \mathrm{ha}$, número que viabiliza o plantio por mudas.

O crescimento inicial da parte aérea da mamoneira é muito lento no primeiro mês após o plantio. Sabendo-se

\footnotetext{
${ }^{1}$ Engenheira Agrônoma, M.Sc. Doutoranda em Agronomia UNESP Jaboticabal - limarosiane@yahoo.com.br

2Pesquisador da Embrapa Algodão - Rua Oswaldo Cruz, 1143 - Campina Grande, PB - liv@cnpa.embrapa.br; nbeltrao@cnpa.embrapa.br

${ }^{3}$ Estudante de Biologia pela Universidade Estadual da Paraíba/UEPB - Estagiária da Embrapa Algodão.

${ }^{4}$ Estudante de Agronomia pela Universidade Federal Rural de Pernambuco/UFRPE - Estagiário da Embrapa Algodão.
} 
que a estação chuvosa na região semi-árida é freqüentemente muito curta e irregular, a disponibilidade de mudas em adiantado estádio de crescimento no início das chuvas, pode tornar-se uma grande vantagem para a cultura, permitindo-lhe estabelecer-se em campo em pouco tempo, levando vantagem sobre as plantas daninhas e aproveitando melhor o período em que há umidade disponível no solo.

Diversos materiais orgânicos e inorgânicos têm sido utilizados para a formulação de substratos, para a produção de mudas, havendo necessidade de se determinar os mais apropriados para cada espécie de forma a atender sua demanda quanto a fornecimento de nutrientes e propriedades físicas como retenção de água, aeração, facilidade para penetração de raízes e não ser favorável à incidência de doenças. O substrato precisa também ser um material abundante na região e ter baixo custo, razão pela qual geralmente se utilizam resíduos agroindustriais. Entre os materiais freqüentemente utilizados como substrato, citam-se: casca de arroz carbonizada (LUCAS et al., 2003), esterco bovino (CAVALCANTI et al., 2002), bagaço de cana (MELO et al., 2003), composto orgânico (TRINDADE et al., 2001), cama de frango e moinha de café (ANDRADE NETO et al., 1999), casca de Acácia-negra (SOUZA et al., 2003) e húmus de minhoca (LIMA et al., 2001).

A definição do tamanho do recipiente para produção da muda é um importante aspecto, pois influencia diversas características da muda e pode impactar o percentual de sobrevivência no campo e a produtividade da cultura. A forma e o tamanho desse recipiente exercem marcada influência sobre o crescimento das raízes e da parte aérea da planta. A altura, a presença de ranhuras e a forma do recipiente também são fundamentais para a correta formação da muda (SOUZA, 1995).

Em recipientes muito altos, a disponibilidade de oxigênio na parte inferior fica reduzida se o substrato não for bem arejado, o que prejudica a respiração e o crescimento radicular e pode propiciar o desenvolvimento de doenças. Recomenda-se que a altura do recipiente seja no máximo $22 \mathrm{~cm}$ para que não haja problemas de aeração (HANDRECK \& BLACK, 1991, citados por SOUZA, 1995).

Quanto ao diâmetro, se o recipiente for muito estreito, após o transplantio as raízes que cresceram para baixo tendem a não crescer lateralmente. No entanto, o crescimento lateral pode ser favorecido por recipientes que tenham ranhuras verticais nas paredes. Em recipientes largos, o problema com o enovelamento das raízes é menor, porém deve-se procurar utilizar o menor recipiente possível para minimizar volume de substrato, espaço em bancadas e facilitar o transporte (SOUZA, 1995).

Quanto ao formato, a maioria dos recipientes é circular, os quais têm a desvantagem de facilitar o enovelamento das raízes, exigindo que se faça poda das raízes antes do plantio. No entanto, Severino et al. (2004a) demonstraram que quando a raiz principal da mamoneira é podada, a planta não produz nova raiz pivotante, resultando em plantas com sistema radicular mal desenvolvido e pouco resistente à baixa disponibilidade de água. Para minimizar o problema do enovelamento, podem-se utilizar recipientes em formato quadrado ou com ranhuras verticais que guiem as raízes para baixo.

Diante do exposto, a escolha do tamanho do recipiente deve ser um ponto de equilíbrio entre o volume e formato que permitam bom crescimento da muda, mas que minimizem os custos de produção.

Com o presente estudo, objetivou-se avaliar a produção de mudas de mamoneira em recipientes de diferentes tamanhos (saquinhos de plástico), utilizando substratos compostos por misturas duplas de solo com diferentes fontes de matéria orgânica.

\section{MATERIAL E MÉTODOS}

$\mathrm{O}$ experimento foi conduzido em casa-devegetação, na Embrapa Algodão, Campina Grande, PB, no período de 3 de maio a 22 de junho de 2004, utilizando sementes da cultivar BRS Nordestina, a qual tem porte médio e boa adaptação ao cultivo na região semi-árida. Adotou-se delineamento em blocos ao acaso, com 4 repetições e 25 tratamentos em distribuição fatorial $5^{2}$, sendo os fatores 5 volumes de recipientes $(0,4 \mathrm{~L}, 0,6 \mathrm{~L}, 1,2 \mathrm{~L}, 2,0 \mathrm{~L}$ e $2,5 \mathrm{~L})$ e cinco composições de substrato (solo misturado na proporção 1:1 v/v com bagaço de cana, casca de amendoim, esterco bovino, mucilagem de sisal e cama de frango). A parcela experimental foi constituída por dois sacos, contendo uma planta cada. A análise química dos materiais utilizados para compor os substratos encontra-se na Tabela 1.

Entre 15 e 43 DAE, fizeram-se cinco coletas destrutivas semanais para obtenção de dados de altura, diâmetro caulinar, área foliar, número de folhas e matéria seca da parte aérea e radicular. A semeadura foi realizada diretamente nos recipientes, plantando-se três sementes por saco para posterior desbaste. A área foliar foi calculada pela fórmula $S=0,2398 \times(L+P)^{1,9259}$, em que $L=$ largura da folha e $\mathrm{P}=$ comprimento da nervura principal(SEVERINO et al., 2004a). Calculou-se o tamanho da folha pela divisão da área foliar pelo número de folhas. 
Os dados obtidos foram submetidos à análise de variância e análise de regressão para o fator quantitativo. As médias dos valores qualitativos foram comparadas pelo Teste de Tukey (1\%) segundo Santos \& Ghey (2003).

\section{RESULTADOS E DISCUSSÃO}

Detectaram-se efeitos significativos (a $1 \%$ pelo Teste F) dos tratamentos sobre todas as variáveis de crescimento estudadas e também nas interações entre os fatores volume e substratos, exceto do substrato composto por mistura de solo e bagaço de cana. Os valores das variáveis de crescimento medidas aos 29, 36 e 43 DAE estão apresentados na Tabela 2, em função do tamanho dos recipientes, e na Tabela 3, em função da composição do substrato. $\mathrm{Na}$ Tabela 4 apresentam-se as equações de regressão das características de crescimento medidas aos 43 DAE em função do volume do recipiente. A equação relativa ao número de folhas não foi apresentada por ter baixo coeficiente de determinação $\left(\mathrm{R}^{2}=0,61\right)$.

$\mathrm{O}$ volume do recipiente teve grande influência sobre o crescimento das mudas de mamoneira, efeito perceptível com maior clareza pela observação dos valores de área foliar e de massa seca da parte aérea e das raízes (Tabela 2). Aos 43 DAE, as mudas cultivadas no recipiente com 2,0 L apresentavam $480,40 \mathrm{~cm}^{2} \mathrm{de}$ área foliar (AF) e 3,83 g de massa seca da parte aérea (MSPA), enquanto aquelas no recipiente de $0,4 \mathrm{~L}$ apresentava $125,61 \mathrm{~cm}^{2}$ de AF e 1,22 g de MSPA. O sistema radicular da mamoneira cresce rapidamente, ocupando em poucos dias todo o volume do substrato, de forma que um recipiente pequeno limita o crescimento da planta, produzindo mudas de baixa qualidade. Entre os recipientes avaliados, constatou-se que aqueles com $2 \mathrm{~L}$ de volume propiciaram bom crescimento em todas as variáveis estudadas até os 43 DAE, sendo, portanto excessivo a adoção de um recipiente com 2,5 litros ou mais para produção de mudas de mamoneira (Tabela 2).

No recipiente de menor volume $(0,4 \mathrm{~L})$ o crescimento das mudas a partir dos 29 DAE foi limitado, como se observa pelos valores de altura, área foliar e massa seca da parte aérea e das raízes. No entanto, as mudas crescidas em recipiente de $2 \mathrm{~L}$ de volume, ainda apresentaram crescimento entre 36 e 43 DAE quando se observam as mesmas características, o que evidencia a limitação causada pelo volume do recipiente.

Observou-se intenso enovelamento das raízes, principalmente nos recipientes de menor volume (Figura 1), o que pode ser muito prejudicial ao crescimento da planta após o transplantio, pois conforme apresentou Severino et al. (2004b), quando as raízes da mamoneira são cortadas, não se recuperam de forma satisfatória. Se houver poda das raízes enoveladas, existe o risco de desenvolvimento insatisfatório do sistema radicular da planta em campo, notadamente da raiz pivotante que tem importante contribuição para a resistência da mamoneira ao estresse hídrico.

Os substratos compostos por mistura de areia e esterco bovino ou casca de amendoim mostraram-se os mais adequados para o crescimento das mudas de mamoneira, (Tabela 3). A casca de amendoim e o esterco bovino possuem boa quantidade de nutrientes, principalmente Nitrogênio (Tabela 1), o que possibilitou bom crescimento das plantas, como se observa pelos valores de área foliar, altura da planta, e massa seca da parte aérea e de raízes (Tabela 3 ).

TABELA 1 - Composição química das fontes de matéria orgânica utilizadas na formulação dos substratos. Campina Grande, PB, 2004.

\begin{tabular}{|c|c|c|c|c|c|c|}
\hline Material & $\mathbf{N}$ & $\mathbf{P}$ & $\mathbf{K}$ & $\mathbf{C a}$ & Mg & Cinzas \\
\hline & & & & & & \\
\hline Bagaço de cana & 0,24 & 0,20 & 0,11 & 0,39 & 0,45 & 18,5 \\
\hline Casca de amendoim & 1,54 & 0,36 & 0,79 & 0,46 & 0,21 & 3,5 \\
\hline Esterco bovino & 0,78 & 0,87 & 0,33 & 0,31 & 0,18 & - \\
\hline Mucilagem de sisal & 0,12 & 0,01 & 0,10 & 0,40 & 0,24 & - \\
\hline Cama de frango & 2,95 & 3,97 & 1,10 & 4,71 & 6,93 & - \\
\hline
\end{tabular}

Análises feitas no Laboratório de Solos da Embrapa Algodão.

Ciênc. agrotec., Lavras, v. 30, n. 3, p. 480-486, maio/jun., 2006 
TABELA 2 - Valores de altura, diâmetro caulinar, número de folhas, área foliar, tamanho da folha, massa seca da parte aérea e massa seca das raízes de mudas de mamoneira cv. BRS (MS) Nordestina, aos 29, 36 e 43 dias após a emergência em recipientes variando de 2,5 a 0,4 litros. Campina Grande, PB, 2004.

\begin{tabular}{|c|c|c|c|c|c|c|c|}
\hline $\begin{array}{l}\text { Volume do } \\
\text { Recipiente }\end{array}$ & $\begin{array}{c}\text { Altura } \\
\text { (cm) }\end{array}$ & $\begin{array}{l}\text { Diâmetro } \\
\text { caulinar } \\
(\mathbf{m m})\end{array}$ & $\begin{array}{c}\mathrm{N}^{\mathbf{0}} \\
\text { folhas }\end{array}$ & $\begin{array}{l}\text { Área foliar } \\
\quad\left(\mathrm{cm}^{2}\right)\end{array}$ & $\begin{array}{c}\text { Tamanho } \\
\text { da folha } \\
\left(\mathrm{cm}^{2}\right)\end{array}$ & $\begin{array}{c}\text { MS parte } \\
\text { aérea (g) }\end{array}$ & $\begin{array}{c}\text { MS } \\
\text { Raízes } \\
\text { (g) }\end{array}$ \\
\hline \multicolumn{8}{|c|}{ 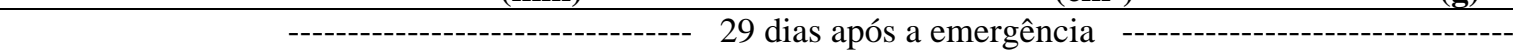 } \\
\hline 2,5 & 18,35 & 5,62 & 4,15 & 321,48 & 73,22 & 2,23 & 0,84 \\
\hline 2,0 & 19,35 & 5,60 & 4,05 & 291,68 & 67,39 & 1,84 & 0,76 \\
\hline 1,2 & 17,85 & 5,02 & 3,75 & 194,64 & 50,90 & 1,32 & 0,50 \\
\hline 0,6 & 16,39 & 4,54 & 3,30 & 144,66 & 42,36 & 1,24 & 0,53 \\
\hline 0,4 & 14,97 & 4,31 & 3,15 & 108,78 & 33,79 & 1,10 & 0,42 \\
\hline \multicolumn{8}{|c|}{---------------------------------- 36 dias após a emergência } \\
\hline 2,5 & 20,08 & 6,18 & 4,95 & 483,86 & 89,59 & 3,68 & 1,51 \\
\hline 2,0 & 20,14 & 6,03 & 4,65 & 414,71 & 81,88 & 3,35 & 1,67 \\
\hline 1,2 & 17,74 & 5,42 & 4,45 & 261,90 & 57,64 & 1,97 & 1,03 \\
\hline 0,6 & 15,70 & 4,69 & 3,90 & 173,42 & 42,87 & 1,36 & 0,77 \\
\hline 0,4 & 15,49 & 4,67 & 3,70 & 125,16 & 32,54 & 1,27 & 0,60 \\
\hline \multicolumn{8}{|c|}{---------------------------------- 43 dias após a emergência --------------------------------- } \\
\hline 2,5 & 18,89 & 5,99 & 4,25 & 410,60 & 89,08 & 3,13 & 1,60 \\
\hline 2,0 & 22,50 & 6,44 & 4,75 & 480,40 & 94,32 & 3,83 & 1,87 \\
\hline 1,2 & 18,63 & 5,33 & 3,95 & 216,32 & 52,15 & 2,02 & 0,92 \\
\hline 0,6 & 16,22 & 4,65 & 4,00 & 165,09 & 39,81 & 1,38 & 0,63 \\
\hline 0,4 & 14,76 & 4,63 & 3,80 & 125,61 & 31,84 & 1,22 & 0,56 \\
\hline
\end{tabular}

TABELA 3 - Valores de altura, diâmetro caulinar, número de folhas, área foliar, tamanho da folha, massa seca da parte aérea e massa seca das raízes de mudas de mamoneira cv. BRS (MS) Nordestina, aos 29, 36 e 43 dias após a emergência, cultivadas em misturas de solo bagaço de cana, casca de amendoim, esterco bovino, mucilagem de sisal e cama de frango. Campina Grande, PB, 2004.

\begin{tabular}{|c|c|c|c|c|c|c|c|}
\hline Substrato & $\begin{array}{c}\text { Altura } \\
(\mathbf{c m})\end{array}$ & $\begin{array}{c}\text { Diâmetro } \\
\text { caulinar } \\
(\mathbf{m m})\end{array}$ & $N^{\circ}$ folhas & $\begin{array}{l}\text { Área foliar } \\
\quad\left(\mathrm{cm}^{2}\right)\end{array}$ & $\begin{array}{l}\text { Tamanho } \\
\text { da folha } \\
\left(\mathrm{cm}^{2}\right)\end{array}$ & $\begin{array}{c}\text { MS } \\
\text { parte } \\
\text { aérea } \\
(\mathrm{g})\end{array}$ & $\begin{array}{c}\text { MS } \\
\text { Raízes } \\
\text { (g) }\end{array}$ \\
\hline & \multicolumn{7}{|c|}{ 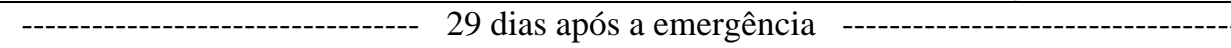 } \\
\hline Bagaço de cana & $17,26 \mathrm{ab}$ & $4,11 \mathrm{~b}$ & $2,55 \mathrm{c}$ & $36,80 \mathrm{~b}$ & $14,54 \mathrm{~b}$ & $0,64 \mathrm{~b}$ & $0,28 \mathrm{~b}$ \\
\hline Casca amendoim & $18,31 \mathrm{ab}$ & $5,18 \mathrm{a}$ & $3,85 \mathrm{ab}$ & $327,02 \mathrm{a}$ & 81,98 a & $1,79 \mathrm{a}$ & $0,93 \mathrm{a}$ \\
\hline Esterco bovino & 20,88 a & 5,65 a & $3,45 \mathrm{bc}$ & $210,04 \mathrm{a}$ & 58,79 a & $1,74 \mathrm{a}$ & $0,28 \mathrm{~b}$ \\
\hline Mucilagem de sisal & $16,64 \mathrm{ab}$ & $4,88 \mathrm{ab}$ & $3,85 \mathrm{abc}$ & 220,98 a & $56,74 \mathrm{a}$ & $1,74 \mathrm{a}$ & $0,95 \mathrm{a}$ \\
\hline \multirow[t]{2}{*}{ Cama de frango } & $13,81 \mathrm{~b}$ & $5,29 \mathrm{a}$ & $4,70 \mathrm{a}$ & $266,41 \mathrm{a}$ & $55,61 \mathrm{a}$ & $1,82 \mathrm{a}$ & $0,60 \mathrm{ab}$ \\
\hline & \multicolumn{7}{|c|}{ 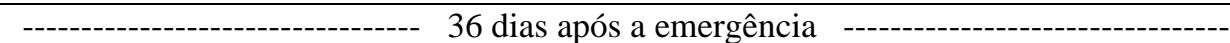 } \\
\hline Bagaço de cana & $17,16 \mathrm{bc}$ & $4,14 \mathrm{c}$ & $3,15 \mathrm{~b}$ & $48,63 \mathrm{c}$ & $15,48 \mathrm{c}$ & $0,55 \mathrm{c}$ & $0,57 \mathrm{c}$ \\
\hline Casca amendoim & $19,95 \mathrm{ab}$ & $6,08 \mathrm{ab}$ & $4,70 \mathrm{a}$ & $501,02 \mathrm{a}$ & $102,92 \mathrm{a}$ & $2,56 \mathrm{~b}$ & $1,39 \mathrm{~b}$ \\
\hline Esterco bovino & $23,01 \mathrm{a}$ & $6,66 \mathrm{a}$ & $4,95 \mathrm{a}$ & $408,84 \mathrm{ab}$ & $77,12 \mathrm{ab}$ & $5,59 \mathrm{a}$ & $2,20 \mathrm{a}$ \\
\hline Mucilagem de sisal & $14,92 \mathrm{c}$ & $5,04 \mathrm{bc}$ & $4,55 \mathrm{a}$ & $268,03 \mathrm{~b}$ & $57,03 \mathrm{~b}$ & $1,53 \mathrm{bc}$ & $0,87 \mathrm{bc}$ \\
\hline \multirow[t]{2}{*}{ Cama de frango } & $14,11 \mathrm{c}$ & $5,09 \mathrm{bc}$ & $4,30 \mathrm{a}$ & $232,52 \mathrm{bc}$ & $51,97 \mathrm{bc}$ & $1,41 \mathrm{bc}$ & $0,54 \mathrm{c}$ \\
\hline & \multicolumn{7}{|c|}{ 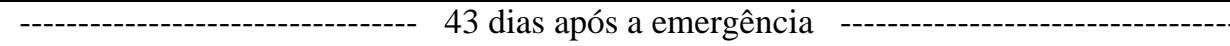 } \\
\hline Bagaço de cana & $16,96 \mathrm{c}$ & $4,20 \mathrm{c}$ & $2,95 \mathrm{~b}$ & $44,47 \mathrm{~d}$ & $15,08 \mathrm{~d}$ & $0,60 \mathrm{~d}$ & $0,41 \mathrm{~d}$ \\
\hline Casca amendoim & $18,25 \mathrm{bc}$ & $5,80 \mathrm{~b}$ & $4,82 \mathrm{a}$ & $459,43 \mathrm{a}$ & 93,05 a & $2,60 \mathrm{~b}$ & $2,04 \mathrm{a}$ \\
\hline Esterco bovino & $23,50 \mathrm{a}$ & $6,31 \mathrm{a}$ & $4,27 \mathrm{a}$ & $348,96 \mathrm{~b}$ & $78,38 \mathrm{~b}$ & $4,64 \mathrm{a}$ & $1,17 \mathrm{~b}$ \\
\hline Mucilagem de sisal & $19,18 \mathrm{~b}$ & $5,42 \mathrm{~b}$ & $4,33 \mathrm{a}$ & $337,39 \mathrm{~b}$ & $75,59 \mathrm{~b}$ & $2,28 \mathrm{~b}$ & $1,37 \mathrm{~b}$ \\
\hline Cama de frango & $13,26 \mathrm{~d}$ & $5,42 \mathrm{~b}$ & $4,39 \mathrm{a}$ & $238,95 \mathrm{c}$ & $51,69 \mathrm{c}$ & $1,64 \mathrm{c}$ & $0,72 \mathrm{c}$ \\
\hline
\end{tabular}


TABELA 4 - Equações de regressão da altura, diâmetro caulinar, área foliar, tamanho da folha, massa seca da parte aérea e massa seca das raízes em função do volume do recipiente em mudas de mamoneira cv. BRS Nordestina aos 43 dias após a emergência.

\begin{tabular}{llc}
\hline Variável & \multicolumn{1}{c}{ Equação } & $\mathbf{R}^{2}$ \\
\hline Altura & $\mathrm{Y}=-3,28 \mathrm{x}^{2}+11,97 \mathrm{x}+10,16$ & 0,88 \\
Diâmetro caulinar & $\mathrm{Y}=-0,43 \mathrm{x}^{2}+2,06 \mathrm{x}+0,91$ & 0,91 \\
Área foliar & $\mathrm{Y}=-39,83 \mathrm{x}^{2}+276,02 \mathrm{x}+6,99$ & 0,87 \\
Tamanho da folha & $\mathrm{Y}=-6,07 \mathrm{x}^{2}+48,02 \mathrm{x}+11,92$ & 0,93 \\
Massa seca da parte aérea & $\mathrm{Y}=-0,49 \mathrm{x}^{2}+2,55 \mathrm{x}+0,09$ & 0,87 \\
Massa seca das raízes & $\mathrm{Y}=-0,17 \mathrm{x}^{2}+1,11 \mathrm{x}+0,06$ & 0,88 \\
\hline
\end{tabular}

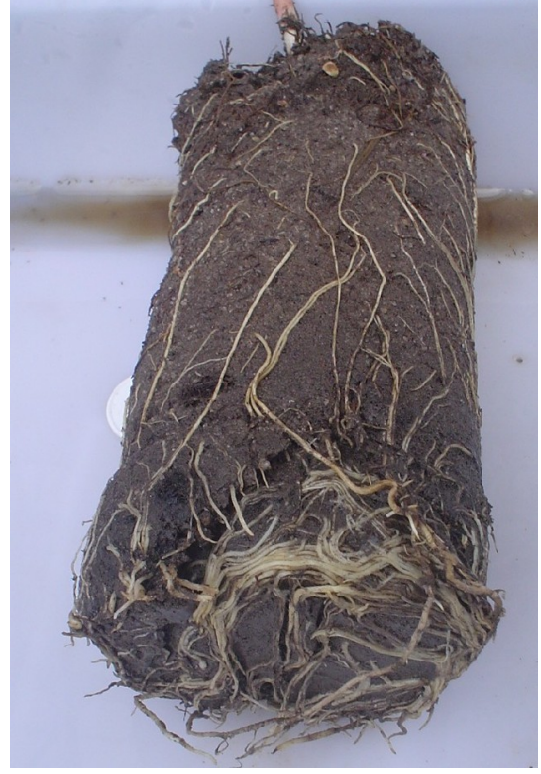

FIGURA 1 - Enovelamento de raízes em mudas de mamoneira cultivar BRS Nordestina em saco de $0,6 \mathrm{~L}$ de volume. Campina Grande, PB, 2004.

A aeração das raízes da mamoneira é muito importante para seu crescimento, como tem sido demonstrado por estudos que mostram seu sofrível crescimento em solos compactados (VALE et al., 2004) e sua extrema sensibilidade ao estresse por anoxia (encharcamento do solo) como verificado por Moraes \& Severino (2004) e Severino et al. (2004b). Por esse motivo, o crescimento das raízes no substrato contendo casca de amendoim destacou-se dos demais substratos porque este material não foi moído e sua granulometria permitiu bom arejamento (Figura 2). Com efeito oposto, o substrato contendo cama de frango, mesmo contendo grande riqueza nutricional (Tabela 1), dificultou o arejamento das raízes e conseqüentemente comprometeu o crescimento das plantas, principalmente na análise feita aos $43 \mathrm{DAE}$, quando a planta apresentava maior demanda por oxigênio nas raízes (Tabela 2). No substrato contendo cama de frango, as plantas não tiveram crescimento significativo após 29 DAE.

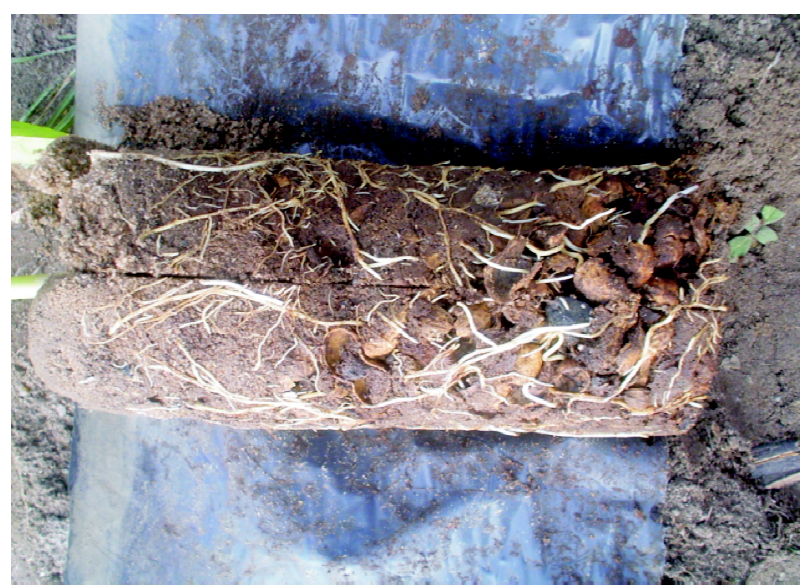

FIGURA 2 - Substrato contendo casca de amendoim, no qual se observa a presença de macroporos e bom desenvolvimento das raízes das mudas de mamoneira. Campina Grande, PB, 2004.

A mucilagem de sisal é um material com teores de nutrientes medianos quando comparados aos demais materiais estudados, no entanto contribui para a melhoria das características físicas do substrato por ter baixa densidade, reter água e ser muito poroso, embora não promova boa agregação radicular.

O bagaço de cana é um material muito pobre em nutrientes (Tabela 1), razão pela qual as mudas não tiveram 
bom crescimento quando ele compôs o substrato, as quais aos 43 DAE apresentavam o menor crescimento em todas as características estudadas, exceto a altura.

Aos 43 DAE, quando o experimento foi finalizado, as mudas já apresentavam tamanho e desenvolvimento suficientes para serem levadas a campo para plantio definitivo, embora o desempenho das mudas plantadas não tenha sido avaliado nesse experimento. Observou-se que uma das limitações na tecnologia de plantio de mamoneira por mudas é que o crescimento dessa planta é muito rápido e o período em que as mudas podem permanecer em viveiro é muito curto. $\mathrm{O}$ momento ideal para transplantio situa-se aproximadamente entre 35 a 50 dias e após esse período elas perdem qualidade por enovelamento e limitação de crescimento das raízes, além da necessidade de maior espaço no viveiro para comportar o crescimento da parte aérea. Observou-se também que as mudas de mamona são muito frágeis e facilmente danificadas pelo manuseio no transporte para o campo e plantio. As raízes têm crescimento rápido, mas são pouco resistentes, e por isso o torrão da muda precisa ser manuseado com cuidado para evitar o rompimento das raízes. Os pecíolos das folhas também são ocos e quebram-se facilmente pelo manuseio inadequado no viveiro ou no transporte para o campo.

\section{CONCLUSÕES}

As mudas de mamoneira da cultivar BRS Nordestina cresceram satisfatoriamente em recipientes com pelo menos 2 L de volume até os 43 dias após a emergência, mas recipientes com volume inferior a $1 \mathrm{~L}$ limitaram o crescimento das plantas.

Os substratos compostos por mistura de areia com casca de amendoim ou esterco bovino propiciaram as melhores condições de crescimento da muda entre os materiais avaliados, enquanto os substratos contendo bagaço de cana e mucilagem de sisal não possibilitaram bons resultados.

\section{AGRADECIMENTOS}

Os autores agradecem o apoio financeiro recebido pela Petrobras para realização deste estudo.

\section{REFERÊNCIAS BIBLIOGRÁFICAS}

ANDRADE NETO, A.; MENDES, A. N. G.; GUIMARÃES, P. T. G. Avaliação de substratos alternativos e tipos de adubação para a produção de mudas de cafeeiro (Coffea arábica L.) em tubetes. Ciência e Agrotecnologia, Lavras, v. 23, n. 2, p. 270-280, 1999.

CAVALCANTI, N. B.; RESENDE, G. M.; BRITO, L. T. L. Emergência e crescimento do imbuzeiro (Spondias tuberosa) em diferentes substratos. Revista Ceres, Viçosa, v. 49, n. 282, p. 97-108, 2002.

LIMA, R. L. S.; FERNANDEZ, V. L. B.; OLIVEIRA, V. H.; HERNANDEZ, F. F. F. Crescimento de mudas de cajueiro anão precoce $\mathrm{CCP}-76$ submetidas a adubação orgânica e mineral. Revista Brasileira de Fruticultura, Jaboticabal, v. 23, n. 2, p. 391-395, 2001.

LUCAS, M. A. K.; SAMPAIO, N. V.; KOHN, E. T.; SOARES, P. F.; SAMPAIO, T. G. Avaliação de diferentes composições de substratos para a aclimatação de mudas de morangueiro (Fragaria $x$ ananassa Duch.). Revista Científica Rural, Bagé, v. 8, n. 1, p. 16-23, 2003.

MELO, A. S.; BRITO, M. E. B.; GOIS, M. P. P.; BARRETO, M. C. V.; VIEGAS, P. R. A.; HOLANDA, F. S. R. Efeito de substratos orgânicos organo-minerais na formação de mudas de maracujazeiro (Passiflora edulis). Revista Científica Rural, Bagé, v. 8, n. 2, p. 116-121, 2003.

MORAES, C. R. A.; SEVERINO, L. S. Influência da saturação hídrica do solo sobre o desenvolvimento da mamoneira. In: CONGRESSO BRASILEIRO DE MAMONA, 1., 2004, Campina Grande. Anais... Campina Grande: Embrapa Algodão, 2004. CD-ROM.

SANTOS, J. W.; GHEY, H. R. (Eds.). Estatística experimental aplicada. Campina Grande: Ed. Marcone, 2003. $213 \mathrm{p}$.

SEVERINO, L. S.; CARDOSO, G. D.; VALE, L. S.; SANTOS, J. W. Método para determinação da área foliar da mamoneira. Revista Brasileira de Oleaginosas e Fibrosas, [S.1.], v. 8, n. 1, p. 753-762, 2004a.

SEVERINO, L. S.; LIMA, C. L. D.; BELTRÃO, N. E. M.; CARDOSO, G. D.; FARIAS, V. A. Mamoneira submetida a encharcamento do solo. In: CONGRESSO BRASILEIRO DE MAMONA, 1., 2004b, Campina Grande. Anais... Campina Grande: Embrapa Algodão, 2004. CD-ROM. 
SOUZA, P. V.; CARNIEL, E.; SCHMITZ, J. A. K.; SILVEIRA, S. V. da. Substratos e fungos micorrízicos arbusculares no desenvolvimento vegetativo de Citrange Troyer. Agropecuária Catarinense, Florianópolis, v. 16, n. 3, p. 84-88, 2003.

SOUZA, P. V. D. Optimización de le produccion de plantones de cítricos en vivero: inoculación con mícorrizas vesiculares arbusculares. 1995. $201 \mathrm{f}$. Tesis (Doctoral) - Universidad Politécnica de Valencia, Valencia, 1995.
TRINDADE, A. V.; MUCHOVEJ, R. M. C.; NEVES, J. C. L.; BARROS, N. F. Crescimento e nutrição de mudas de Eucaliptus grandis em resposta a composto orgânico ou adubação mineral. Revista Ceres, Viçosa, v. 276, n. 48, p. 181-194, 2001.

VALE, L. S.; COSTA, J. V. T.; LIMA, R. L. S.; SILVA, M. I. L.; SEVERINO, L. S.; BELTRÃO, N. E. M.; CARDOSO, G. D. Crescimento da mamoneira em solo compactado. In: CONGRESSO BRASILEIRO DE MAMONA, 1., 2004, Campina Grande. Anais... Campina Grande: Embrapa Algodão, 2004. CD-ROM.

Ciênc. agrotec., Lavras, v. 30, n. 3, p. 480-486, maio/jun., 2006 